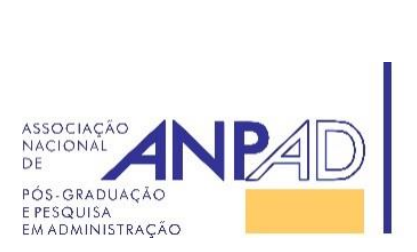
Disponível em
http://www.anpad.org.br/rac
RAC, Rio de Janeiro, v. 21, Edição Especial FCG, art. 5, pp. 84-109, Abril 2017

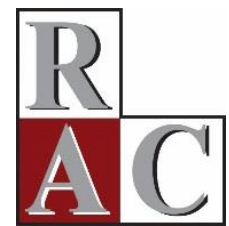

\title{
Efeito de Crise Econômica sobre Escolhas de Ativos para Investimentos Pessoais
}

\author{
Economic Crisis Effect on Asset Choices for Personal Investments
}

Israel José dos Santos Felipe ${ }^{1,2}$ Marcelo Daniel Araújo Ermel ${ }^{1,3}$ Luis Felipe Pilati Cassius ${ }^{1}$ Wesley Mendes-da-Silva ${ }^{1}$

Fundação Getulio Vargas ${ }^{1}$ Universidade Federal de Ouro Preto ${ }^{2}$ Universidade Federal do Rio Grande do Norte ${ }^{3}$ 


\title{
Resumo
}

A literatura econômica documenta que eventos extremos podem induzir alterações na propensão ao risco. Este estudo investiga se a crise 2008/2009 afetou o comportamento de investimento em diversos ativos, financeiros e reais, por parte de dezenas de milhares de cidadãos residentes em diversas regiões dos Estados Unidos. Os resultados obtidos por meio de modelos logit sugerem que a crise de 2008/2009 pode ter induzido significativa mudança na preferência por diferentes ativos, tais como trusts, títulos de dívida, imóveis, e planejamento da aposentadoria. Os resultados deste estudo podem ser contributivos para políticas públicas acerca do comportamento de investimento das famílias, especialmente mediante contexto de crise, além de orientar a proposição de novos produtos financeiros por parte da indústria financeira.

Palavras-chave: crise do subprime; decisões de investimentos; ativos financeiros; finanças pessoais; survey of consumer finances.

\begin{abstract}
The economic literature documents that extreme events can induce changes in risk propensity. This study investigates if the 2008/2009 crisis affected the investment behavior of tens of thousands of citizens living in different regions of the United States for different assets. The results obtained by means of logit models suggest that the crisis of 2008/2009 may have induced significant changes in investment preferences for different assets such as trust, bonds, real estate, and retirement planning. This study's results may contribute to public policies concerning household investment behavior, especially during times of crisis, in addition to guiding the proposal of new financial products by the finance industry.
\end{abstract}

Key words: subprime crisis; investment decisions; financial assets; personal finances; survey of consumer finances. 


\section{Introdução e Motivação}

De maneira inesperada e severa, a crise econômica de 2008/2009 é considerada sem precedentes na era pós II Grande Guerra. Os efeitos dessa crise apresentaram-se mais explícitos a partir de dezembro de 2007, sendo que todos os países ao redor do mundo experimentaram alguma consequência econômica negativa decorrente dessa crise (Necker \& Ziegelmeyer, 2016). Um dos países mais fortemente atingidos foram os Estados Unidos, com impactos em diferentes níveis, desde o macroeconômico até o cidadão (O’Neill \& Xiao, 2012).

Eventos raros, como crises, podem induzir aumento da aversão ao risco por parte dos indivíduos (Said, Afzal, \& Turner, 2015). Por sua vez, a teoria microeconômica frequentemente assume que a disposição a tomar risco diminui com a redução de riqueza (Gollier, 2004). Ao menos para a maioria dos cidadãos dos Estados Unidos, a crise de 2008/2009, conhecida como crise dos Subprime, ocasionou queda de seu nível de riqueza. Desse modo, espera-se que a preferência por determinados investimentos pessoais sofra algum tipo de alteração, tendo em vista que, invariavelmente, investimentos sugerem tomada de algum risco (Dimmock, Kouwenberg, Mitchell, \& Peijnenburg, 2016).

Contudo, a literatura mais recente que investiga se a disposição a tomar risco sofre impactos por parte de crises não tem oferecido evidências acerca das preferências por determinados tipos de ativos financeiros ou reais, por ocasião da crise 2008/2009 (Guiso, Sapienza, \& Zingales, 2015; Hoffmann, Post, \& Pennings, 2013; Weber, Weber, \& Nosic, 2013). A questão acerca de como eventos raros e dramáticos, e.g. crises econômicas de alcance internacional, afeta expectativas e a tomada de risco permanece aberta (Necker \& Ziegelmeyer, 2016).

A partir dessa visão, este artigo verifica associações entre atitude em relação ao risco, bem como expectativas futuras, e a preferência por determinados ativos para investimentos pessoais. Em adição, são apresentadas evidências mediante uma abordagem comparada antes e depois do momento mais crítico da crise 2008/2009. A análise emprega dados disponibilizados pelo Survey of Consumer Finances (SCF), referentes a dezenas de milhares de cidadãos, nos anos de 2007 (pré-crise) e 2013 (pós-crise, pois, já em 2011 o Produto Interno Bruto dos Estados Unidos havia retornado ao nível de 2007).

O trabalho concentra-se na identificação de associações entre preferência por determinados ativos, tais como ativos de renda fixa, renda variavel, imóveis, entre outros com disposição ao risco e expectativas dos cidadãos mediante o controle para variáveis demográficas, em linha com agenda de pesquisa apontada pela literatura de finanças no nível pessoal (Hoffmann, et al., 2013; Mugerman, Ofir, \& Wiener, 2016; Necker \& Ziegelmeyer, 2016; Taylor et al., 2010; Weber et al., 2013; Zick, Mayer, \& Glaubitz, 2012).

A pesquisa ao redor de finanças pessoais não é necessariamente algo novo (Wisman, 2014). Acerca do comportamento financeiro em contexto de crises econômicas, Hoffmann, Post e Pennings (2013) encontraram resultados que sugerem que a percepção de risco não é uniforme entre os investidores durante crises. Isto é, tolerância e percepção de risco apresentam-se menos voláteis do que expectativas de retorno. Em adição, durante os momentos mais agudos da crise, tanto a tolerância ao risco quanto as expectativas de retorno decrescem, enquanto a percepção de risco aumenta. Ao final das crises, por sua vez, a percepção de risco dos investidores tenderia a retornar ao seu estado original (Hoffmann et al., 2013).

Ainda a esse respeito, outros autores têm abordado diferenças de comportamentos decorrentes de gênero (Fisher, 2010), grau de instrução financeira (Cooper \& Zhu, 2016; Schuchardt et al., 2009), região geográfica (Kimball \& Shumway, 2006), ou etnia (Fontes \& Kelly, 2013). Diversas linhas teóricas ao redor de aspectos comportamentais surgiram para explicar fenômenos que influenciam as atitudes financeiras de famílias e indivíduos, como o herd behavior e a loss aversion (Kahneman \& Tversky, 1979). 
O presente estudo contribui para a literatura, já que analisa escolhas individuais de ativos financeiros em condições adversas, i.e., crise econômica, especificamente a crise do Subprime nos Estados Unidos. Entende-se que esse argumento reafirma a contribuição deste estudo para a literatura de finanças, seja de mercados maduros ou emergentes, tal como o Brasil. Destaque-se que a realidade brasileira se apresenta, ao menos por ora, carente de estudos, estritamente pela inexistência de dados de natureza ao menos semelhante.

Em adição, o Brasil, desde 2015, início do segundo governo Dilma Rousseff, enfrenta a mais aguda crise econômica já experimentada pelo país. Além disso, a demanda por investimentos pessoais, especialmente da previdência privada, tem sido evidente, como reflexo do conhecimento difundido da necessidade de esforços individuais dirigidos à complementação dos valores percebidos a título de aposentadoria.

Este artigo está organizado em cinco seções. Na primeira, é apresentada a introdução do trabalho, bem como a motivação pela escolha do tema. Na segunda seção, é feita a revisão da literatura correlata. A terceira seção descreve o método adotado no desenvolvimento do trabalho. Na quarta seção, são apresentados e discutidos os resultados empíricos alcançados. A quinta, e última, seção destina-se a apresentar as considerações finais e as implicações do estudo.

\section{Estrutura Teórica e Literatura Relacionada}

Um dos primeiros e principais autores dedicados aos padrões de poupança e consumo foi Keynes (1936). Seu trabalho Absolute Income Hypothesis tem servido de suporte para diversos outros estudos que pautaram as teorias mais recentes. Nesse trabalho, Keynes (1936) explicava o consumo como uma função da renda líquida de impostos $Y_{t}$ em um período $t$, e da propensão marginal a consumir $\lambda$, sendo portanto: $C_{t}=\lambda$. $Y_{t}$ (Keynes, 1936). No entanto, esse modelo pouco explicava o comportamento de consumo no longo prazo, e a inclinação do indivíduo a poupar, embora Keynes (1936) tenha sido um dos primeiros a admitir a relevância de estudos comportamentais em Finanças, quando enfatizava a importância do animal spirit.

Com o intuito de contribuir para a maior completude das discussões iniciadas por Keynes (1936), Modigliani e Brumberg (1954) propuseram a Life-Cycle Hypothesis. Essa teoria foi aplicada inicialmente sobre as decisões individuais de consumo e poupança. A principal contribuição dela foi a inclusão de variáveis como: a riqureza, o número de anos esperado até a aposentadoria, e o número de anos esperado até o falecimento.

Modigliani e Brumberg (1954) assumem um modelo com cinco principais variáveis: T, que representa anos de vida restantes; $\mathrm{W}$, que se refere à riqueza do indivíduo; $\mathrm{Y}$, que representa a renda anual; R, que indica o número de anos até a aposentadoria; e $\mathrm{C}$, que representa o consumo. Assim, o modelo que define a função de consumo é expresso por (1):

$$
\mathrm{C}=\frac{\mathrm{W}+\mathrm{RY}}{\mathrm{T}}
$$

Essa função informa que o indivíduo constrói seu patrimônio acumulando uma poupança até a idade da aposentadoria, momento a partir do qual gastará tudo o que poupou. O modelo de consumo, por sua vez, mantém-se constante por todo o período (Bunting, 2001).

Embora o modelo de Modigliani e Brumberg (1954) seja mais aplicável no longo prazo do que o de Keynes, Friedman (1957) criticou aspectos dessa linha teórica, por não explicar completamente os comportamentos de consumo. Uma das principais críticas foi que os aposentados podem não gastar sua poupança de maneira tão ágil quanto descrevem Modigliani e Brumberg (1954), hipoteticamente em decorrência de dois argumentos principais: (a) os aposentados são cautelosos em relação a despesas imprevistas; e (b) os aposentados deixam heranças para seus familiares (Friedman, 1957). 
Nessa perspectiva, Friedman (1957) desenvolveu a Permanent Income Hypothesis, a qual descreve como os indivíduos tomam decisões de consumo ao longo da vida. Essa teoria supõe que o padrão de consumo de um indivíduo não se baseia na sua renda atual, mas sim na sua expectativa média de renda no longo prazo. Essa expectativa, é chamada de Permanent Income, e é determinada pelos ativos físicos (ações, debêntures e propriedades) e humanos (educação e experiência) de cada indivíduo.

Ao longo do tempo, os estudos sobre o padrão de gerenciamento financeiro das famílias e indivíduos, liderados por Keynes (1936), tornaram-se cada vez mais relevantes. Suas implicações estendiam-se tanto para empresas de consumo, bancos e instituições financeiras, como para as instituições públicas, principalmente em termos de suporte para decisões macroeconômicas. Uma ampla literatura sobre decisões das famílias foi desenvolvida com o objetivo de incluir as interações entre as famílias no modelo neoclássico de análise de demanda (Barnett, 1981).

A partir da criação do Survey of Consumer Finances (SCF), em 1962, diversos estudos foram desenvolvidos para identificar aspectos relativos a diferentes grupos demográficos, explorando evidências do contexto dos Estados Unidos. A esse respeito, MacGregor, Slovic, Berry, e Evensky (1999), partindo da crítica à visão da teoria econômica clássica (tal como também assume o Capital Asset Pricing Model), i.e., existência de eficiência do mercado e correlação positiva entre risco e retorno, apontam preocupações acerca de tais premissas.

Assim, MacGregor et al. (1999) ressaltam a necessidade de rediscutir a premissa de que o risco seria um barômetro para decisões de investimento, o que posteriormente seria também assumido por Fama e French (1992). MacGregor et al. (1999) encontraram indícios de significância da não linearidade entre percepção de risco e retorno/risco. Ou seja, o risco percebido e a relação retorno/risco estariam relacionados mediante uma função $\mathrm{U}$ invertido.

Um estudo que se destacou pela utilização dos dados do SCF foi o de Campbell (2006), o qual concentrou-se nas decisões financeiras das famílias. A sua principal contribuição foi a descoberta de elementos subjetivos que estavam incorporados em decisões no nível das famílias (o principal foi a ingenuidade), os quais inibiam o oferecimento de novos produtos financeiros por parte das instituições financeiras, em função do despreparo financeiro evidenciado pelos indivíduos.

Korniotis e Kumar (2011) realizaram um estudo sobre as decisões de investimento de indivíduos idosos, e concluíram que indivíduos idosos aplicam seus conhecimentos financeiros com menor eficácia, e demonstram menor habilidade com investimentos, o que em parte deve-se à queda da capacidade cognitiva, decorrente do aumento da idade (Kalaycı \& Serra-Garcia, 2016). Esses efeitos tornam-se ainda mais significantes quando são observados idosos com menor nível de instrução, com menores receitas, e/ou que pertencem a minorias étnicas. Finke, Howe e Huston (2017) apontam que o conhecimento em finanças decresce um ponto percentual a cada ano depois dos sessenta anos de idade.

Em relação ao nível de conhecimento financeiro individual, Lusardi (2012) afirma que o nível de sofisticação financeira é deficiente para indivíduos com mais de cinquenta e cinco anos de idade. Além disso, muitos indivíduos com idade superior a cinquenta e cinco anos não dominam aspectos básicos acerca de: apreçamento de ativos, diversificação de riscos, escolha de portfólio e custos de transação. Desse modo, a falta de conhecimentos financeiros básicos pode ter consequências expressivas, principalmente em períodos de crise nos quais diversos indivíduos perdem suas poupanças acumuladas ao longo de sua vida (Lusardi, 2012).

Os estudos de Yoong (2011) e Hilgert, Hogarth e Beverly (2003) sugerem que o nível de educação financeira é menor entre os mais jovens. Esse fato, como descreve Lusardi (2012), tem consequências diretas sobre os comportamentos dos indivíduos, sendo esses menos inclinados a poupar para a aposentadoria (Lusardi \& Mitchell, 2007), ou investir em ações (Kimball \& Shumway, 2006). Além disso, esses indivíduos tendem a usar canais mais onerosos de empréstimos (Lusardi, 2009), e a escolher fundos de investimento submetidos a taxas de administração mais elevadas (Hastings \& Tejeda-Ashton, 2008). 
O’Neill e Xiao (2012) analisaram os efeitos da crise sobre os hábitos financeiros de indivíduos e famílias, eles concluem que diversos comportamentos financeiros (e.g. orçar, poupar e gastar) foram alterados entre os períodos de pré e pós-crise. Devlin-Foltz e Sabelhaus (2016), utilizando dados do SCF, constataram que choques de renda e de riqueza estão associados a alterações expressivas nos comportamentos de consumo.

Zick, Mayer e Glaubitz (2012) investigaram as diversas respostas de diferentes gerações à grande crise de 2008/2009 nos EUA. Seus principais achados sugerem que as gerações mais velhas (Younger boomer e Older boomer) são mais propensas à contratação de um planejador financeiro, comparativamente às mais novas (Generation $Y$ e Generation $X$ ), ao invés de buscarem maior conhecimento financeiro, e as gerações mais velhas tornaram-se menos propensas a poupar, e mais inclinadas a procrastinar a aposentadoria. Essas gerações também buscaram maior segurança para seus investimentos de aposentadoria, enquanto as gerações mais novas demonstraram maior tolerância a risco. Essas evidências motivaram testes de efeitos quadráticos da idade (Bruin, 2011).

Alguns estudos recentes sugerem existência de mudança nos gastos dos consumidores, frente a incertezas no âmbito do contexto macroeconômico que sucedeu a crise de 2008 nos EUA. A esse respeito, relata-se que os consumidores se tornaram mais propensos a economizar, como consequência da crise (Egol, Clyde, Rangan, \& Sanderson, 2010). A literatura documenta evidências de que os norteamericanos estavam menos convictos de que possuíam fundos suficientes em suas aposentadorias para manter seus respectivos padrões de vida (The Hartford, 2009).

\section{Método}

\section{Base de dados e variáveis}

Para analisar a propensão a investir em determinados ativos, a título de investimentos pessoais pelos indivíduos, antes e depois da crise de 2008/2009, foram utilizados dados do Survey of Consumer Finances (SCF) nos períodos de 2007 (pré-crise) e 2013 (pós-crise). O SCF é um estudo transversal trienal realizado com as famílias norte-americanas, patrocinado pelo Federal Reserve Board, em cooperação com o Departamento do Tesouro norte-americano.

Os dados do SCF incluem informações sobre os balanços das famílias, pensões, renda e características demográficas. Nas edições de 2007 e 2013, o SCF indicou a participação de 22.085 e 30.075 respondentes, respectivamente. Para elaborar uma análise sobre as principais mudanças ocorridas nos períodos anterior e posterior à crise 2008/2009, foram testados modelos de regressão logística estimados com o emprego de variáveis selecionadas com base na literatura corrente (Finke, Howe, \& Huston, 2017; Fisher, 2010; O’Neill \& Xiao, 2012). A Tabela 1 apresenta as variáveis independentes e dependentes. 
Tabela 1

\section{Descrição das Variáveis Independentes Adotadas na Pesquisa}

\begin{tabular}{|c|c|}
\hline Variável & Descrição \\
\hline \multicolumn{2}{|l|}{ Painel A: Variáveis independentes } \\
\hline Idade & Idade do respondente expressa em anos \\
\hline Gênero & Igual a 1 se masculino, e 0 no caso alternativo \\
\hline Estado civil & Igual a 1 se casado, e 0 no caso alternativo \\
\hline Nível de Instrução & $\begin{array}{l}\text { Igual a } 1 \text { se o respondente possui ensino superior completo, e } 0 \text { no caso } \\
\text { alternativo }\end{array}$ \\
\hline Número de dependentes & $\begin{array}{l}\text { Número de pessoas que integram o círculo de dependência da família do } \\
\text { respondente }\end{array}$ \\
\hline $\begin{array}{l}\text { Expectativa para os próximos } \\
\text { cinco anos }\end{array}$ & $\begin{array}{l}\text { Indica o grau de expectativa do respondente para a economia nos próximos } \\
\text { cinco anos, recebe valor igual a } 1 \text { se existe expectativa de piora, } 2 \\
\text { manutenção do cenário atual, e } 3 \text { se expectativa de melhora. }\end{array}$ \\
\hline $\begin{array}{l}\text { Horizonte de planejamento } \\
\text { financeiro }\end{array}$ & $\begin{array}{l}\text { Indica o horizonte de planejamento financeiro do respondente, recebe valor } \\
\text { igual a } 1 \text { se o horizonte de planejamento é de próximos meses, } 2 \text { se próximo } \\
\text { ano, } 3 \text { se próximos } 5-10 \text { anos, e } 4 \text { para mais de } 10 \text { anos. }\end{array}$ \\
\hline Inclinação ao risco & $\begin{array}{l}\text { Indica a propensão ao risco do respondente, recebe valor igual a } 1 \text { quando } \\
\text { não está disposto a correr riscos, } 2 \text { quando está disposto a correr riscos } \\
\text { dentro da média, } 3 \text { quando está disposto a correr riscos acima da média, e } 4 \\
\text { quando está disposto a correr riscos significantes, }\end{array}$ \\
\hline $\begin{array}{l}\text { Expectativa sobre a pensão a ser } \\
\text { recebida na aposentadoria }\end{array}$ & $\begin{array}{l}\text { Indica as expectativas sobre a renda a ser recebida na aposentadoria, que } \\
\text { varia de } 1 \text { (totalmente inadequada) a } 5 \text { (muito satisfatória). }\end{array}$ \\
\hline $\begin{array}{l}\text { Necessidade de poupança para } \\
\text { ocasiões de emergência }\end{array}$ & $\begin{array}{l}\text { Valor em moeda (US\$) que indica a necessidade de poupança estimada pelo } \\
\text { respondente para situações inusitadas ou de emergência (variável contínua). }\end{array}$ \\
\hline Ocupação & $\begin{array}{l}\text { Conjunto de variáveis dummy que indica a ocupação do respondente: } \\
\text { Estudante, Dono de casa, Aposentado e Trabalhador, que são } 1 \text { nos casos } \\
\text { positivos, e } 0 \text { nos casos alternativos }\end{array}$ \\
\hline Raça & $\begin{array}{l}\text { Conjunto de variáveis dummy que reflete a raça do respondente: Negro, } \\
\text { Branco e Latino, que são } 1 \text { nos casos positivos, e } 0 \text { nos casos alternativos }\end{array}$ \\
\hline
\end{tabular}

Painel B: Variáveis dependentes

Propriedades privadas ou bens imóveis

Participação societária em empresas de capital fechado

Contas de aposentadoria

CDB's (Certificados de Depósito Bancário)

Poupanças

Fundos de investimento
Igual a 1 se o respondente é proprietário de algum bem imóvel, e zero no caso alternativo.

Igual a 1 se o respondente tem participação ou sociedade em alguma empresa de capital fechado, e zero no caso alternativo.

Igual a 1 se o respondente tem algum tipo de plano de aposentadoria (nos EUA, os principais são chamados de IRA Accounts e Keogh Accounts); e zero no caso alternativo.

Igual a 1 se o respondente tem algum tipo de certificado de depósito de alguma instituição financeira, e zero no caso alternativo.

Igual a 1 se o respondente tem algum tipo de conta poupança, incluindo depósitos para a Faculdade, e zero no caso alternativo.

Igual a 1 se o respondente tem algum tipo de fundo de investimento que não possa ser incluído nas categorias anteriores, e zero no caso alternativo. 


\section{Tabela 1 (continuação)}

\begin{tabular}{ll}
\hline Variável & Descrição \\
\hline Títulos de renda fixa & $\begin{array}{l}\text { Igual a } 1 \text { se o respondente detém algum título de renda fixa, seja corporativo } \\
\text { ou público, e zero no caso alternativo. }\end{array}$ \\
Ações & $\begin{array}{l}\text { Igual a } 1 \text { se o respondente possui ações de companhias abertas negociadas } \\
\text { na Bolsa de Valores, e zero no caso alternativo. }\end{array}$ \\
Anuidades ou Pensões & $\begin{array}{l}\text { Igual a } 1 \text { se o respondente tem algum tipo de renda proporcionado por } \\
\text { algum ativo que ofereça o pagamento de anuidades, e zero no caso } \\
\text { alternativo. }\end{array}$ \\
Trusts & $\begin{array}{l}\text { Igual a } 1 \text { se o respondente tem algum tipo de conta gerida por terceiros, e } \\
\text { zero no caso alternativo. }\end{array}$ \\
\hline
\end{tabular}

Nota. A fonte de todas as variáveis foi o Social Security Administration. (2013). Social security changes. Retrieved from https://www.ssa.gov/news/press/factsheets/colafacts2013.pdf; Survey of Consumer Finances. (n.d.). Database. Retrieved 24 February, 2017 from https://www.federalreserve.gov/econresdata/scf/scfindex.htm

\section{Estratégia de identificação}

O procedimento utilizado para a análise dos dados foi a regressão logística, tendo como variáveis dependentes cada um dos onze produtos financeiros e reais constantes do SCF, buscando identificação nas associações entre as expectativas e a propensão a risco dos indivíduos, mediante o controle de características demográficas, a alocar recursos financeiros em determinados ativos.

Os resultados empíricos foram diagnosticados e analisados com base em quatro diferentes métricas de ajuste dos modelos: (a) percentagem de casos classificados corretamente; (b) R-Quadrado de McFadden (Aldrich \& Nelson, 1984); (c) critério de Akaike; e (d) log da verossimilhança. Esses critérios foram escolhidos para consolidar as análises estatísticas realizadas, conforme recomendam Wasserstein e Lazar (2016) e Brodeur, Lé, Sangnier e Zylberberg (2016), os quais defendem que a análise de significância estatística deve ser acompanhada de medidas alternativas de ajustamento dos modelos.

Conforme Wasserstein e Lazar (2016), a discussão dos resultados ocorre mediante a consideração de um contexto econômico e social, com o fim de validar empiricamente as suposições subjacentes dos dados (Wasserstein \& Lazar, 2016). Para verificar os efeitos (para além da simples adição, conforme Bettis, Ethiraj, Gambardella, Helfat, \& Mitchell, 2016) de duas ou mais variáveis nos modelos estatísticos, foram considerados termos de interação, construídos a partir de variáveis originais da base de dados do SCF. Esses termos indicam se uma variável independente produz um efeito diferente na variável dependente devido à interferência de outra variável independente. Os modelos estatísticos obtidos via regressões logit foram obtidos conforme (2):

$$
\begin{aligned}
& \text { Preferência pelo ativo }_{i}=\varphi_{0}+\varphi_{1} \text { Horizonte de planejamento }_{i}+ \\
& \varphi_{2} \text { Inclinação ao risco }_{i}+\varphi_{3} \text { Expectativa para aposentadoria }_{i}+ \\
& \varphi_{4} \text { Necessidade de poupar }_{i}+\varphi_{5} \text { Expectativa para os próximos anos }+\varphi_{6} X+\varepsilon_{i}
\end{aligned}
$$

Em se tratando de possíveis preocupações com endogeneidade, seguindo procedimento adotado na literatura correlata (Necker \& Ziegelmeyer, 2016), neste estudo optou-se por adotar um conjunto diversificado de variáveis de controle: idade, gênero, estado civil, número de dependentes, ocupação, e raça. Um potencial problema da estratégia de identificação adotada é a possibilidade de viés de variável omitida, uma das fontes de endogeneidade, que poderia ser endereçada, se acaso houvesse disponibilidade de dados que permitisse estimação de regressões com dados em painel, como estratégia empírica (Basinger \& Ensley, 2010; Lewbel, Dong, \& Yang, 2012; Roberts \& Whited, 2013). Contudo, entende-se que os resultados obtidos não estão comprometidos, tendo em vista que não foi encontrada correlação entre o termo de erro e os regressores do modelo binário (Basinger \& Ensley, 2010). 
Percebe-se que, em 2007, os respondentes, em média, possuíam idade de $\sim 52$ anos, tinham mais de 2 dependentes, tipicamente esperavam que o cenário econômico para os próximos cinco anos fosse mantido, adotavam horizonte de planejamento para o próximo ano, estavam dispostos a riscos médios, possuíam expectativa de receber a pensão na aposentadoria parcialmente inadequada, e apontavam necessidade de poupança para emergências futuras ao redor de 284 mil dólares.

\section{Resultados Empíricos}

A Tabela 2 apresenta as estatísticas descritivas das variáveis adotadas no presente estudo.

Tabela 2

Características Demográficas dos Participantes da Pesquisa

\begin{tabular}{|c|c|c|c|c|}
\hline \multirow[t]{2}{*}{ Painel A: Variáveis contínuas } & \multicolumn{2}{|c|}{ Antes da crise } & \multicolumn{2}{|c|}{ Depois da crise } \\
\hline & Média & DP & Média & DP \\
\hline Idade & 51,82 & 16,07 & 51,75 & 16,17 \\
\hline \# de dependentes & 2,53 & 1,40 & 2,50 & 1,41 \\
\hline Expectativa para cinco anos & 1,99 & 0,77 & 2,28 & 0,76 \\
\hline Horizonte de planejamento & 3,24 & 1,33 & 2,92 & 1,38 \\
\hline Inclinação a risco & 2,01 & 0,86 & 1,87 & 0,84 \\
\hline Expectativa de aposentadoria & 2,46 & 1,31 & 2,43 & 1,27 \\
\hline Necessidade de poupança (\$) & 284.224 & 2.534 .000 & 194.004 & 2.153 .040 \\
\hline \multirow[t]{2}{*}{ Painel B: Variáveis Discretas } & \multicolumn{2}{|c|}{ Antes da crise } & \multicolumn{2}{|c|}{ Depois da crise } \\
\hline & Freq. & $\%$ & Freq. & $\%$ \\
\hline Homens & 17.555 & 79,5 & 22.960 & 76,3 \\
\hline Mulheres & 4.530 & 20,5 & 7.115 & 23,7 \\
\hline Casados & 13.460 & 60,9 & 16.390 & 54,5 \\
\hline Solteiros & 8.625 & 39,1 & 13.685 & 45,5 \\
\hline Ensino superior & 9.897 & 44,8 & 12.761 & 42,4 \\
\hline Sem ensino superior & 12.188 & 55,2 & 17.314 & 57,6 \\
\hline \multicolumn{5}{|l|}{ Ocupação } \\
\hline Trabalhador & 17.080 & 77,3 & 22.320 & 74,2 \\
\hline Estudante & 210 & 1 & 490 & 1,6 \\
\hline Dono de casa & 295 & 1,3 & 400 & 1,3 \\
\hline Aposentado & 4.000 & 18,1 & 5525 & 18,4 \\
\hline Desempregado & 500 & 2,3 & 1.340 & 4,5 \\
\hline \multicolumn{5}{|l|}{ Raça } \\
\hline Negro & 2.051 & 9,33 & 3.731 & 12,4 \\
\hline Branco & 4.500 & 79,6 & 22.123 & 73,6 \\
\hline Latino & 1.565 & 7,1 & 2.781 & 9,2 \\
\hline Outros & 884 & 4,0 & 1.440 & 4,8 \\
\hline
\end{tabular}




\section{Tabela 2 (continuação)}

\begin{tabular}{ll}
\hline Painel C: Teste $\chi^{2}$ & (Antes e depois da crise) \\
\hline Homens e mulheres & 0,242 \\
Casados e solteiros & 0,246 \\
Ensino superior e s/ ensino sup. & 0,659 \\
Trabalhador & 0,905 \\
Estudante & $0,000^{* *}$ \\
Dono de casa & 0,642 \\
Desempregado & 0,159 \\
Negro & $0,002 * *$ \\
Branco & $0,000 * *$ \\
Latino & 0,374 \\
\hline
\end{tabular}

Nota. Esta tabela apresenta as estatísticas descritivas de cada uma das variáveis independentes utilizada na pesquisa. $* * *$ p-value $<0,01 ; * *$ p-value $<0,05 ; *$ p-value $<0,1$. Antes $=2007 ;$ Depois $=2013$.

Após o período mais grave da crise, em 2013, a situação geral pouco se alterou. Em essência, o horizonte de planejamento ficou entre os próximos cinco ou dez anos, com necessidade estimada de poupança para emergências futuras ao redor de 194 mil dólares. Com relação ao perfil dos participantes, a maioria foi de indivíduos do sexo masculino, casados, sem ensino superior, trabalhadores e de cor branca, para os dois anos da pesquisa (2007 e 2013).

A seguir estão apresentadas as estimações obtidas (Tabela 3 a 7). Observa-se, na Tabela 3, que, em 2007, a maioria dos detentores de bens imóveis era de indivíduos brancos, solteiros, com nível superior, donos de casa, com um maior número de dependentes, maior horizonte de planejamento, menos expectativa sobre o valor a ser recebido como aposentadoria, e com maior inclinação ao risco, possuindo pelo menos um imóvel antes da crise de 2008/2009.

Tabela 3

Modelo Preditivo para Propriedade e Empresa

\begin{tabular}{|c|c|c|c|c|}
\hline & \multicolumn{2}{|l|}{ Propriedade } & \multicolumn{2}{|l|}{ Empresa } \\
\hline & Antes & Depois & Antes & Depois \\
\hline \multirow[t]{2}{*}{ Horizonte de Planejamento } & $0.0397 * * *$ & $0.0378 * * *$ & $0.0411 * * *$ & $0.0291 * * *$ \\
\hline & $(0.00292)$ & $(0.00200)$ & $(0.00274)$ & $(0.00179)$ \\
\hline \multirow[t]{2}{*}{ Inclinação ao Risco } & $0.111 * * *$ & $0.0742 * * *$ & $0.0945^{* * *}$ & $0.0761 * * *$ \\
\hline & $(0.00459)$ & $(0.00315)$ & $(0.00431)$ & $(0.00281)$ \\
\hline \multirow[t]{2}{*}{ Expectativa Aposentadoria } & 0.00370 & $0.0141 * * *$ & $0.00790 *$ & $0.00938 * * *$ \\
\hline & $(0.00473)$ & $(0.00329)$ & $(0.00436)$ & $(0.00309)$ \\
\hline \multirow[t]{2}{*}{ Necessidade Poupança } & $6.94 \mathrm{e}-08 * * *$ & $3.83 \mathrm{e}-08 * * *$ & $9.45 \mathrm{e}-08 * * *$ & $5.23 \mathrm{e}-08 * * *$ \\
\hline & $(2.62 \mathrm{e}-08)$ & $(1.26 \mathrm{e}-08)$ & $(1.51 \mathrm{e}-08)$ & $(1.13 \mathrm{e}-08)$ \\
\hline \multirow[t]{2}{*}{ Expectativa } & $-0.00464 *$ & $-0.00993 * * *$ & $-0.0342 * * *$ & $-0.0248 * * *$ \\
\hline & $(0.00275)$ & $(0.00203)$ & $(0.00261)$ & $(0.00189)$ \\
\hline
\end{tabular}




\section{Tabela 3 (continuação)}

\begin{tabular}{|c|c|c|c|c|}
\hline & \multicolumn{2}{|l|}{ Propriedade } & \multicolumn{2}{|l|}{ Empresa } \\
\hline & Antes & Depois & Antes & Depois \\
\hline \multirow[t]{2}{*}{ Idade } & $0.0327 * * *$ & $0.0251 * * *$ & $0.0161 * * *$ & $0.0140 * * *$ \\
\hline & $(0.00185)$ & $(0.00122)$ & $(0.00168)$ & $(0.00106)$ \\
\hline \multirow[t]{2}{*}{ Idade $^{2}$} & $-0.000208 * * *$ & $-0.000157 * * *$ & $-0.000124 * * *$ & $-6.79 \mathrm{e}-05^{* * *}$ \\
\hline & $(1.47 \mathrm{e}-05)$ & $(1.02 \mathrm{e}-05)$ & $(1.43 e-05)$ & $(9.50 \mathrm{e}-06)$ \\
\hline \multirow[t]{2}{*}{ Gênero } & $0.229 * * *$ & $0.239 * * *$ & -0.0307 & $0.0849 *$ \\
\hline & $(0.0709)$ & $(0.0602)$ & $(0.0729)$ & $(0.0463)$ \\
\hline \multirow[t]{2}{*}{ Estado Civil } & $0.0871 * * *$ & $0.0732 * * *$ & $0.0834 * * *$ & $0.0481 * * *$ \\
\hline & $(0.0106)$ & $(0.00756)$ & $(0.00985)$ & $(0.00663)$ \\
\hline \multirow[t]{2}{*}{ Instrução } & $0.157 * * *$ & $0.119 * * *$ & $0.123 * * *$ & $0.102 * * *$ \\
\hline & $(0.00764)$ & $(0.00525)$ & $(0.00704)$ & $(0.00496)$ \\
\hline \multirow[t]{2}{*}{ \# de dependentes } & $0.0198 * * *$ & $0.00633 * * *$ & $0.0172 * * *$ & $0.0156^{* * *}$ \\
\hline & $(0.00318)$ & $(0.00228)$ & $(0.00290)$ & $(0.00191)$ \\
\hline \multicolumn{5}{|l|}{ Ocupação } \\
\hline \multirow[t]{2}{*}{ Trabalhador } & 0.0457 & $0.111 * * *$ & $0.341 * * *$ & $0.181 * * *$ \\
\hline & $(0.0314)$ & $(0.0175)$ & $(0.0432)$ & $(0.0177)$ \\
\hline \multirow[t]{2}{*}{ Estudante } & -0.0126 & -0.0776 & 0.105 & $0.126 * * *$ \\
\hline & $(0.0878)$ & $(0.0598)$ & $(0.0828)$ & $(0.0382)$ \\
\hline \multirow[t]{2}{*}{ Dono de casa } & $0.197 * * *$ & $0.159 * * *$ & $0.246^{* * * *}$ & $0.0718 * *$ \\
\hline & $(0.0420)$ & $(0.0291)$ & $(0.0608)$ & $(0.0327)$ \\
\hline \multirow[t]{2}{*}{ Aposentado } & 0.0201 & $0.0749 * * *$ & $0.0919 * *$ & $-0.0387 * *$ \\
\hline & $(0.0328)$ & $(0.0190)$ & $(0.0449)$ & $(0.0195)$ \\
\hline \multicolumn{5}{|l|}{ Raça } \\
\hline \multirow[t]{2}{*}{ Negro } & -0.0211 & $0.143 * * *$ & -0.0699 & -0.0239 \\
\hline & $(0.0687)$ & $(0.0536)$ & $(0.0740)$ & $(0.0416)$ \\
\hline \multirow[t]{2}{*}{ Branco } & $0.170 * * *$ & $0.146 * * *$ & $0.121 *$ & 0.0206 \\
\hline & $(0.0610)$ & $(0.0521)$ & $(0.0651)$ & $(0.0389)$ \\
\hline \multirow[t]{2}{*}{ Latino } & 0.123 & 0.0300 & -0.164 & -0.0109 \\
\hline & $(0.0761)$ & $(0.0629)$ & $(0.102)$ & $(0.0476)$ \\
\hline \multirow[t]{2}{*}{ Idade*Gênero } & -0.000278 & $6.60 \mathrm{e}-05$ & $0.00566 * * *$ & 0.000256 \\
\hline & $(0.000684)$ & $(0.000464)$ & $(0.000873)$ & $(0.000458)$ \\
\hline \multirow[t]{2}{*}{ Gênero*Negro } & 0.0460 & $-0.242 * * *$ & -0.121 & -0.0358 \\
\hline & $(0.0733)$ & $(0.0558)$ & $(0.0786)$ & $(0.0442)$ \\
\hline \multirow[t]{2}{*}{ Gênero*Branco } & -0.103 & $-0.121 * *$ & -0.0903 & 0.0176 \\
\hline & $(0.0638)$ & $(0.0534)$ & $(0.0672)$ & $(0.0403)$ \\
\hline
\end{tabular}


Tabela 3 (continuação)

\begin{tabular}{lllll}
\hline & Propriedade & \multicolumn{3}{l}{ Empresa } \\
\cline { 2 - 5 } & Antes & Depois & Antes & Depois \\
\hline Gênero*Latino & -0.0899 & -0.0808 & 0.0967 & -0.0141 \\
& $(0.0802)$ & $(0.0647)$ & $(0.104)$ & $(0.0497)$ \\
\hline $\mathrm{N}$ & 22.085 & 30.075 & 22.085 & 30.075 \\
R-quadrado de McFadden & 0,230 & 0,249 & 0,279 & 0,267 \\
Log da verossimilhança & $-11.141,29$ & $-13.446,83$ & $-9991,46$ & $-12.262,53$ \\
Critério de Akaike & $22.328,580$ & $26.939,650$ & $20.028,920$ & $24.571,070$ \\
\% Previstos Corretamente & $75,3 \%$ & $78,8 \%$ & $77,9 \%$ & $81,3 \%$ \\
\hline
\end{tabular}

Nota. $* * *$ p-value $<0,01 ; * *$ p-value $<0,05 ; *$ p-value $<0,1$. Erro-padrão da estimativa está entre parênteses. Antes = 2007; Depois $=2013$. Coeficientes estimados via comando 'margins, $\operatorname{dydx}(*)$, atmeans' do Stata.

É importante ressaltar que, em 2007 (com base nas variáveis significantes), o fato do indivíduo ser dono de casa aumentava a probabilidade deste ser proprietário de imóvel em quase $20 \%$, ser branco também aumentava a probabilidade em quase $20 \%$, ser homem em $22 \%$ (p-value < 0,01 ), e ter um maior nível de instrução em 15,7\% (p-value <0,01). Foi nesse período que parece ter havido certo relaxamento sistemático da regulamentação financeira americana, e um consequente e expressivo aumento na concessão de hipotecas para as classes sociais mais abastadas. Em 2013, observa-se alteração do conjunto de variáveis significantes.

Isto é, mulheres negras tinham uma probabilidade $24 \%$ menor de adquirir imóveis. Resultados semelhantes foram verificados para gênero e branco, só que mulheres brancas tinham uma redução de metade, ou seja, $12 \%$ na probabilidade. Tanto para a Propriedade quanto para Empresa, o termo quadrático da Idade apresentou comportamento negativo em ambos os anos. As variáveis Idade, Estado Civil, Instrução, Unidade Familiar e Expectativa para a economia nos próximos anos tiveram influência positiva e significante tanto para a propriedade quanto para a empresa.

De modo geral, essas informações sugerem que, quanto maior for a educação de um indivíduo, e maior a sua expectativa para a economia no futuro, maior tende a ser sua propensão a investir em um bem imóvel. Com respeito à participação societária em empresas de capital fechado, a variável Gênero não se revelou significante. No período anterior à crise, as pessoas eram predominantemente casadas, com nível superior, com horizonte de planejamento mais longo, mais dispostas a assumir riscos, com baixa expectativa de aposentadoria, trabalhadores ou donos de casa com maior propensão à participação societária em negócios privados.

De 2007 para 2013, a importância da Instrução sofreu certa redução, ao redor de 2pp. Ou seja, de $12 \%$ para $10 \%$. O horizonte de planejamento e a propensão a risco também tiveram redução de influência. Em 2007, o trabalhador apresentava uma probabilidade de 34 contra 18\% em 2013. Todavia, estudante, que não era determinante em 2007, em 2013 aumentou a probabilidade de ser proprietário de empresa em $12 \%$. O Dono de casa, em 2007, aumentava em $24 \%$ a probabilidade, enquanto, em 2013, era de apenas 7\%, e o aposentado, que antes aumentava em 9\%, passou a diminuir em 3\%.

Os modelos para os Planos de Aposentadoria são apresentados na Tabela 4. Nesses casos, verificou-se que os indivíduos mais inclinados a investir em contas de aposentadoria e CDB são predominantemente pessoas com ensino superior, com unidades familiares menores, expectativas econômicas positivas para os cinco anos subsequentes, maior horizonte de planejamento financeiro e aposentados. 
Tabela 4

Modelo Preditivo para Conta de Aposentadoria e CDB

\begin{tabular}{|c|c|c|c|c|}
\hline & \multicolumn{2}{|c|}{ Conta de Aposentadoria } & \multicolumn{2}{|l|}{ CDB } \\
\hline & Antes & Depois & Antes & Depois \\
\hline \multirow[t]{2}{*}{ Horizonte de planejamento } & $0.0538 * * *$ & $0.0436 * * *$ & $0.0191 * * *$ & $0.0117 * * *$ \\
\hline & $(0.00316)$ & $(0.00231)$ & $(0.00203)$ & $(0.00107)$ \\
\hline \multirow[t]{2}{*}{ Inclinação a risco } & $0.108 * * *$ & $0.109 * * *$ & -0.00180 & -0.00235 \\
\hline & $(0.00510)$ & $(0.00406)$ & $(0.00307)$ & $(0.00178)$ \\
\hline \multirow[t]{2}{*}{ Expectativa } & $0.0119 * *$ & $0.0357 * * *$ & 0.00170 & $0.00764 * * *$ \\
\hline & $(0.00512)$ & $(0.00404)$ & $(0.00320)$ & $(0.00188)$ \\
\hline \multirow[t]{2}{*}{ Necessidade poupança } & $-1.04 \mathrm{e}-09$ & $4.26 \mathrm{e}-09$ & $-2.03 e-09$ & $3.15 \mathrm{e}-10$ \\
\hline & $(1.23 \mathrm{e}-09)$ & $(2.92 \mathrm{e}-09)$ & $(2.07 \mathrm{e}-09)$ & $(3.23 \mathrm{e}-10)$ \\
\hline \multirow[t]{2}{*}{ Expectativa aposentadoria } & $0.00959 * * *$ & $0.0127 * * *$ & $0.00518 * * *$ & $0.00547 * * *$ \\
\hline & $(0.00299)$ & $(0.00246)$ & $(0.00179)$ & $(0.00101)$ \\
\hline \multirow[t]{2}{*}{ Idade } & $0.0350 * * *$ & $0.0330 * * *$ & $0.00638 * * *$ & $-0.00209 * * *$ \\
\hline & $(0.00185)$ & $(0.00139)$ & $(0.00115)$ & $(0.000557)$ \\
\hline \multirow[t]{2}{*}{ Idade $^{2}$} & $-0.000257 * * *$ & $-0.000238 * * *$ & $-2.07 \mathrm{e}-05^{* *}$ & $4.03 \mathrm{e}-05^{* * *}$ \\
\hline & $(1.56 \mathrm{e}-05)$ & $(1.21 \mathrm{e}-05)$ & $(9.36 \mathrm{e}-06)$ & $(4.55 \mathrm{e}-06)$ \\
\hline \multirow[t]{2}{*}{ Gênero } & $0.226 * * *$ & $0.139 * * *$ & $0.0749 *$ & -0.0264 \\
\hline & $(0.0631)$ & $(0.0445)$ & $(0.0402)$ & $(0.0173)$ \\
\hline \multirow[t]{2}{*}{ Estado Civil } & $0.125^{* * *}$ & $0.174 * * *$ & $0.0821 * * *$ & $0.0250 * * *$ \\
\hline & $(0.0116)$ & $(0.00940)$ & $(0.00786)$ & $(0.00433)$ \\
\hline \multirow[t]{2}{*}{ Instrução } & $0.264 * * *$ & $0.227 * * *$ & $0.0526 * * *$ & $0.0326 * * *$ \\
\hline & $(0.00823)$ & $(0.00636)$ & $(0.00561)$ & $(0.00317)$ \\
\hline \multirow[t]{2}{*}{ \# de dependentes } & $-0.00960 * * *$ & $-0.0156 * * *$ & $-0.00537 * *$ & $-0.00315^{* *}$ \\
\hline & $(0.00353)$ & $(0.00286)$ & $(0.00236)$ & $(0.00130)$ \\
\hline \multicolumn{5}{|l|}{ Ocupação } \\
\hline \multirow[t]{2}{*}{ Trabalhador } & $0.0693 * *$ & $0.0656^{* * *}$ & $0.0617 * *$ & $0.0195^{* *}$ \\
\hline & $(0.0329)$ & $(0.0177)$ & $(0.0249)$ & $(0.00951)$ \\
\hline \multirow[t]{2}{*}{ Estudante } & -0.0124 & -0.0553 & 0.0124 & -0.0182 \\
\hline & $(0.0649)$ & $(0.0415)$ & $(0.0491)$ & $(0.0192)$ \\
\hline \multirow[t]{2}{*}{ Dono de casa } & $-0.227 * * *$ & $0.114 * * *$ & $0.128 * * *$ & 0.0156 \\
\hline & $(0.0573)$ & $(0.0316)$ & $(0.0308)$ & $(0.0150)$ \\
\hline \multirow[t]{2}{*}{ Aposentado } & $0.105^{* * *}$ & $0.133 * * *$ & $0.106 * * *$ & 0.0165 \\
\hline & $(0.0349)$ & $(0.0196)$ & $(0.0258)$ & $(0.0101)$ \\
\hline
\end{tabular}




\section{Tabela 4 (continuação)}

\begin{tabular}{|c|c|c|c|c|}
\hline & \multicolumn{2}{|c|}{ Conta de Aposentadoria } & \multicolumn{2}{|l|}{ CDB } \\
\hline & Antes & Depois & Antes & Depois \\
\hline \multicolumn{5}{|l|}{ Raça } \\
\hline \multirow[t]{2}{*}{ Negro } & $-0.110 * *$ & $-0.126^{* * *}$ & $-0.153 * * *$ & $-0.134 * * *$ \\
\hline & $(0.0548)$ & $(0.0367)$ & $(0.0378)$ & $(0.0152)$ \\
\hline \multirow[t]{2}{*}{ Branco } & $0.168 * * *$ & 0.0426 & 0.0146 & $-0.0572 * * *$ \\
\hline & $(0.0486)$ & $(0.0339)$ & $(0.0313)$ & $(0.0121)$ \\
\hline \multirow[t]{2}{*}{ Latino } & $-0.201 * * *$ & $-0.179 * * *$ & -0.0305 & $-0.0912 * * *$ \\
\hline & $(0.0745)$ & $(0.0466)$ & $(0.0408)$ & $(0.0183)$ \\
\hline \multirow[t]{2}{*}{ Idade*Gênero } & $-0.00218 * * *$ & $-0.00350 * * *$ & $-0.001000^{* *}$ & $-0.00118 * * *$ \\
\hline & $(0.000658)$ & $(0.000488)$ & $(0.000393)$ & $(0.000192)$ \\
\hline \multirow[t]{2}{*}{ Gênero*Negro } & $-0.171 * * *$ & -0.0594 & 0.00744 & $0.131 * * *$ \\
\hline & $(0.0631)$ & $(0.0419)$ & $(0.0421)$ & $(0.0183)$ \\
\hline \multirow[t]{2}{*}{ Gênero*Branco } & $-0.0979 *$ & 0.0226 & $-0.0782 * *$ & $0.0822 * * *$ \\
\hline & $(0.0529)$ & $(0.0366)$ & $(0.0333)$ & $(0.0142)$ \\
\hline \multirow[t]{2}{*}{ Gênero*Latino } & 0.0581 & -0.0128 & $-0.113 * *$ & $0.0585^{* * *}$ \\
\hline & $(0.0796)$ & $(0.0511)$ & $(0.0445)$ & $(0.0216)$ \\
\hline $\mathrm{N}$ & 22.085 & 30.075 & 22.085 & 30.075 \\
\hline R-quadrado de McFadden & 0,245 & 0,263 & 0,085 & 0,085 \\
\hline Log da verossimilhança & $-11.402,91$ & $-14.494,11$ & $-9.799,23$ & $-8.141,88$ \\
\hline Critério de Akaike & $22.851,820$ & $29.034,230$ & $19.644,460$ & $16.329,760$ \\
\hline$\%$ Previstos corretamente & $73,7 \%$ & $77,0 \%$ & $81,0 \%$ & $91,3 \%$ \\
\hline
\end{tabular}

Nota. Erro-padrão da estimativa está entre parênteses. Antes = 2007; Depois $=2013$.

Coeficientes estimados via comando 'margins, $\operatorname{dydx}(*)$, atmeans' do Stata. ***p-value $<0,01$; **p-value $<0,05$; *p-value $<$ 0,1 .

Para 2013, a expectativa para o futuro aumentou seu impacto marginal na probabilidade em $2 \%$. Enquanto em 2007 ser Dono de casa diminuía a probabilidade em 11\%, em 2013 aumentava essa probabilidade em $22 \%$, mostrando uma mudança de comportamento desses indivíduos. Entre os termos de interação, deve-se destacar que o coeficiente de Idade*Gênero foi significante e negativo para os dois períodos. Esse resultado sugere que, quanto maior a idade do indivíduo, menor a sua propensão a aderir a um plano de aposentadoria.

Esse resultado apoia os achados de Moore e Mitchell (1997), assim como está em linha com as informações apresentadas no report da Social Security Administration (2013). Antes da crise, ser mulher e negra diminuía a probabilidade de ter uma conta de aposentadoria em 17\%; no período pós-crise, essa característica perdeu sua significância (ver Figura 1). Para o CDB, é possível verificar que, em 2007, a maior inclinação a consumir esses produtos era de indivíduos mais velhos, casados, com ensino superior, unidades familiares menores, maiores horizontes de planejamento e expectativas de aposentadoria mais elevadas. Em 2013, a propensão a comprar CDB's diminuiu com a idade. Ou seja, quanto mais velho o indivíduo, menor sua propensão a consumir esse tipo de produto financeiro. 


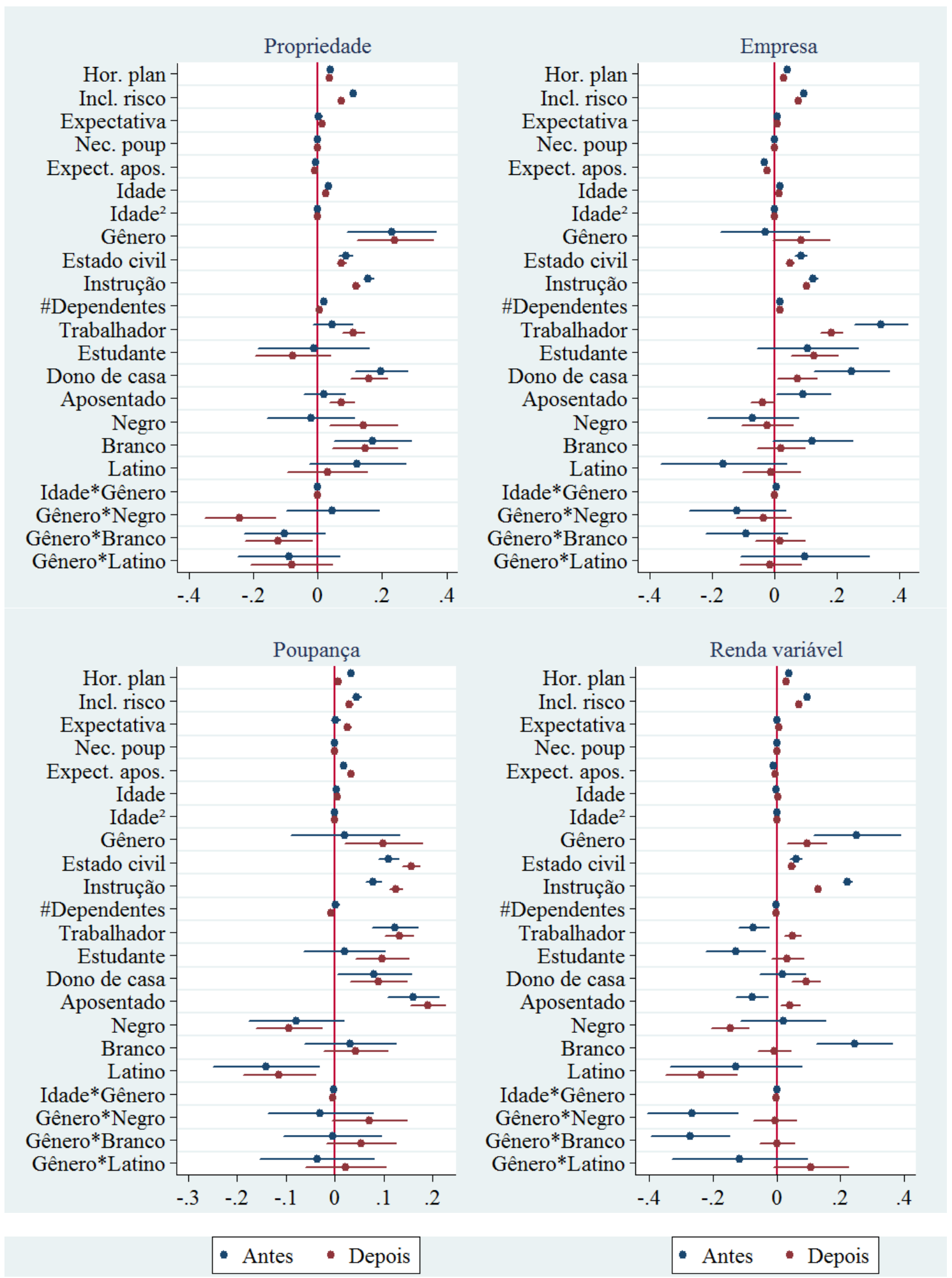

Figura 1. Efeito Marginal das Variáveis Independentes sobre a Propensão a Investir em Diferentes Ativos Financeiros

Esta figura ilustra o efeito marginal (Williams, R. (2012). Using the margins command to estimate and interpret adjusted predictions and marginal e effects. The Stata Journal, 12(2), 308-331) de cada variável explicativa sobre a propensão a investir em diferentes ativos financeiros: Propriedade de imóveis, sociedade em empresas, Poupança e ações, respectivamente no sentido horário. Fonte: Elaborado pelos autores com base nos cálculos realizados.

Destaca-se ainda que a raça se tornou relevante. Ou seja, os resultados sugerem que indivíduos negros, brancos e latinos reduziram sua propensão a adquirir CDB's como modo de investimento, além da expectativa acerca da economia ter se tornado significante, os critérios dono de casa e aposentado 
não são mais relevantes para escolher esse produto. A Tabela 5 apresenta os resultados obtidos para as Conta de Poupança e os Fundos de Investimento. Neste caso, caracterizam-se como potenciais consumidores de poupança: as pessoas casadas, com ensino superior, horizontes de planejamento mais longos, maior inclinação a risco, expectativas positivas sobre as pensões de aposentadoria e não estudantes.

Tabela 5

Modelo Preditivo para Poupança e Fundos de Investimento

\begin{tabular}{|c|c|c|c|c|}
\hline & \multicolumn{2}{|l|}{ Poupança } & \multicolumn{2}{|c|}{ Fundos de Investimento } \\
\hline & Antes & Depois & Antes & Depois \\
\hline \multirow[t]{2}{*}{ Horizonte de planejamento } & $0.0326^{* * *}$ & $0.00751 * * *$ & $0.0355^{* * *}$ & $0.0225^{* * *}$ \\
\hline & $(0.00281)$ & $(0.00236)$ & $(0.00214)$ & $(0.00105)$ \\
\hline \multirow[t]{2}{*}{ Inclinação a risco } & $0.0450 * * *$ & $0.0292 * * *$ & $0.0510^{* * *}$ & $0.0325^{* * *}$ \\
\hline & $(0.00465)$ & $(0.00402)$ & $(0.00311)$ & $(0.00165)$ \\
\hline \multirow[t]{2}{*}{ Expectativa } & 0.00141 & $0.0261 * * *$ & $0.0114 * * *$ & $0.0117 * * *$ \\
\hline & $(0.00461)$ & $(0.00402)$ & $(0.00327)$ & $(0.00165)$ \\
\hline \multirow[t]{2}{*}{ Necessidade de poupança } & $-5.17 \mathrm{e}-09 * * *$ & $-9.95 e-10$ & $2.10 \mathrm{e}-08 * * *$ & $1.22 \mathrm{e}-08 * * *$ \\
\hline & $(1.79 \mathrm{e}-09)$ & $(1.35 \mathrm{e}-09)$ & $(2.83 \mathrm{e}-09)$ & $(1.70 \mathrm{e}-09)$ \\
\hline \multirow[t]{2}{*}{ Expectativa aposentadoria } & $0.0191 * * *$ & $0.0331 * * *$ & 0.000847 & $-0.00342 * * *$ \\
\hline & $(0.00278)$ & $(0.00254)$ & $(0.00186)$ & $(0.000932)$ \\
\hline \multirow[t]{2}{*}{ Idade } & $0.00341 * *$ & $0.00445^{* * *}$ & $0.0101 * * *$ & $0.00562 * * *$ \\
\hline & $(0.00143)$ & $(0.00120)$ & $(0.00118)$ & $(0.000696)$ \\
\hline \multirow[t]{2}{*}{ Idade $^{2}$} & $-5.98 \mathrm{e}-05 * * *$ & $-5.66 \mathrm{e}-05^{* * *}$ & $-5.42 \mathrm{e}-05^{* * *}$ & $-2.71 \mathrm{e}-05^{* * * *}$ \\
\hline & $(1.30 \mathrm{e}-05)$ & $(1.11 \mathrm{e}-05)$ & $(9.88 \mathrm{e}-06)$ & $(5.49 \mathrm{e}-06)$ \\
\hline \multirow[t]{2}{*}{ Gênero } & 0.0207 & $0.0994 * *$ & $0.0981 * *$ & $0.0500 * *$ \\
\hline & $(0.0566)$ & $(0.0405)$ & $(0.0452)$ & $(0.0241)$ \\
\hline \multirow[t]{2}{*}{ Estado civil } & $0.109 * * *$ & $0.156^{* * *}$ & $0.0308^{* * *}$ & $0.0214 * * *$ \\
\hline & $(0.0105)$ & $(0.00883)$ & $(0.00764)$ & $(0.00392)$ \\
\hline \multirow[t]{2}{*}{ Instrução } & $0.0791 * * *$ & $0.125 * * *$ & $0.172 * * *$ & $0.0898 * * *$ \\
\hline & $(0.00785)$ & $(0.00680)$ & $(0.00539)$ & $(0.00317)$ \\
\hline \multirow[t]{2}{*}{ \# de dependentes } & 0.00199 & $-0.00705^{* * *}$ & 0.00114 & $0.00271 * *$ \\
\hline & $(0.00314)$ & $(0.00266)$ & $(0.00220)$ & $(0.00111)$ \\
\hline \multicolumn{5}{|l|}{ Ocupação } \\
\hline \multirow[t]{2}{*}{ Trabalhador } & $0.123 * * *$ & $0.132 * * *$ & $0.0811^{* * *}$ & $0.0595^{* * *}$ \\
\hline & $(0.0238)$ & $(0.0148)$ & $(0.0269)$ & $(0.0107)$ \\
\hline \multirow[t]{2}{*}{ Estudante } & 0.0199 & $0.0961 * * *$ & $0.117 * *$ & $0.0867 * * *$ \\
\hline & $(0.0423)$ & $(0.0277)$ & $(0.0471)$ & $(0.0170)$ \\
\hline \multirow[t]{2}{*}{ Dono de casa } & $0.0810^{* *}$ & $0.0897 * * *$ & $0.123 * * *$ & $0.0475^{* *}$ \\
\hline & $(0.0390)$ & $(0.0296)$ & $(0.0361)$ & $(0.0195)$ \\
\hline \multirow[t]{2}{*}{ Aposentado } & $0.161 * * *$ & $0.190 * * *$ & $0.114 * * *$ & $0.0741 * * *$ \\
\hline & $(0.0265)$ & $(0.0178)$ & $(0.0278)$ & $(0.0112)$ \\
\hline
\end{tabular}




\section{Tabela 5 (continuação)}

\begin{tabular}{lllll}
\hline & Poupança & & \multicolumn{2}{l}{ Fundos de Investimento } \\
\cline { 2 - 5 } & Antes & Depois & Antes & Depois \\
\hline Raça & & & & \\
\hline Negro & -0.0791 & $-0.0936^{* * *}$ & -0.0704 & $-0.0934^{* * *}$ \\
& $(0.0496)$ & $(0.0342)$ & $(0.0435)$ & $(0.0220)$ \\
\hline Branco & 0.0316 & 0.0425 & 0.0437 & -0.00340 \\
& $(0.0472)$ & $(0.0330)$ & $(0.0368)$ & $(0.0181)$ \\
\hline Latino & $-0.140^{* *}$ & $-0.113^{* * *}$ & 0.00706 & $-0.0803^{* *}$ \\
& $(0.0549)$ & $(0.0376)$ & $(0.0483)$ & $(0.0331)$ \\
\hline Idade*Gênero & $-0.00203^{* * *}$ & $-0.00450^{* * *}$ & $-0.000888 *$ & $-0.000862^{* * *}$ \\
& $(0.000513)$ & $(0.000419)$ & $(0.000471)$ & $(0.000268)$ \\
\hline Gênero*Negro & -0.0295 & $0.0712^{*}$ & -0.0224 & $0.0598^{* *}$ \\
\hline Gênero*Branco & $(0.0549)$ & $(0.0392)$ & $(0.0484)$ & $(0.0237)$ \\
\hline Gênero*Latino & -0.00412 & 0.0543 & -0.0208 & 0.0190 \\
& $(0.0510)$ & $(0.0365)$ & $(0.0388)$ & $(0.0189)$ \\
\hline N & -0.0362 & 0.0224 & $-0.110 * *$ & 0.0349 \\
R-quadrado de McFadden & $(0.0596)$ & $(0.0420)$ & $(0.0525)$ & $(0.0348)$ \\
Log da verossimilhança & 22.085 & 30.075 & 22.085 & 30.075 \\
Critério de Akaike & 0,056 & 0,064 & 0,217 & 0,276 \\
\% Previstos corretamente & $-14.282,62$ & $-19.337,42$ & $-9.283,75$ & $-9.204,72$ \\
\hline & $28.611,230$ & $38.720,830$ & $18.613,500$ & $18.455,440$ \\
& $63,0 \%$ & $63,6 \%$ & $78,4 \%$ & $85,9 \%$ \\
\hline
\end{tabular}

Nota. $* * *$-value $<0,01 ; * * p$-value $<0,05 ; *$-value $<0,1$. Erro-padrão da estimativa está entre parênteses. Antes = 2007; Depois $=2013$. Coeficientes estimados via comando 'margins, $\operatorname{dydx}(*)$, atmeans' do Stata.

Em 2013, verifica-se que a variável gênero passou a ser relevante, aumentando a probabilidade de poupança em $9 \%$, bem como o tamanho da unidade familiar, que obteve um coeficiente negativo após a crise, diminuindo a probabilidade em $0,7 \%$, indicando que homens e mulheres tiveram escolhas de investimento diferentes e que, quanto maior a unidade familiar, menor a propensão de consumo da conta de poupança. O produto também se tornou mais popular entre estudantes, aumentando a probabilidade em $9 \%$, ao passo que negros e latinos se tornaram menos propensos a consumi-lo.

Para fundos de investimento, os respondentes mais inclinados a consumir esse tipo de produto são predominantemente: homens, casados, com ensino superior, expectativas econômicas positivas (em cinco anos), maiores horizontes de planejamento e maior inclinação ao risco. Um fato interessante é que, em 2007, o termo de interação entre gênero e a variável latino foi significante. Assim, ser mulher e latina diminuía a probabilidade do individuo investir em fundos de investimento em $11 \%$.

Em 2013, as principais mudanças para fundos de investimento foram o ganho de relevância do tamanho da unidade familiar, da raça (negro ou latino), ambos com menor probabilidade de investir nesses ativos, com $9 \%$ e $8 \%$ a menos, respectivamente, e da expectativa de renda na aposentadoria. Desse modo, quanto maior a expectativa de renda na aposentadoria de um indivíduo, menor sua tendência a aplicar em fundos de investimento.

A Tabela 6 apresenta os resultados para os títulos de renda fixa e variável. Constata-se que os respondentes mais inclinados a consumir produtos de renda fixa eram predominantemente, antes da 
crise: brancos, casados, com ensino superior, com unidades familiares pequenas, maiores horizontes de planejamento, maior inclinação ao risco e com expectativas maiores de renda para a aposentadoria. Entre 2007 a expectativa em relação a economia diminuía a probabilidade do indivíduo em investir em renda fixa em 1\%, enquanto, em 2013, aumentava em $0,6 \%$.

Tabela 6

Modelo Preditivo para Títulos de Renda Fixa e Renda Variável (Ações)

\begin{tabular}{|c|c|c|c|c|}
\hline & \multicolumn{2}{|l|}{ Renda fixa } & \multicolumn{2}{|c|}{ Renda variável } \\
\hline & Antes & Depois & Antes & Depois \\
\hline \multirow{2}{*}{ Horizonte de planejamento } & $0.0194 * * *$ & $0.0147 * * *$ & $0.0384 * * *$ & $0.0313^{* * *}$ \\
\hline & $(0.00222)$ & $(0.00131)$ & $(0.00263)$ & $(0.00151)$ \\
\hline \multirow[t]{2}{*}{ Inclinação a risco } & $0.0153 * * *$ & $0.0140 * * *$ & $0.0972 * * *$ & $0.0708 * * *$ \\
\hline & $(0.00335)$ & $(0.00213)$ & $(0.00411)$ & $(0.00256)$ \\
\hline \multirow[t]{2}{*}{ Expectativa } & $-0.0112 * * *$ & $0.00630 * * *$ & 0.00216 & $0.00795 * * *$ \\
\hline & $(0.00356)$ & $(0.00213)$ & $(0.00421)$ & $(0.00253)$ \\
\hline \multirow[t]{2}{*}{ Necessidade de poupança } & $9.28 \mathrm{e}-09 * * *$ & $4.85 \mathrm{e}-09 * * *$ & $9.25 \mathrm{e}-09^{*}$ & $1.68 \mathrm{e}-08 * * *$ \\
\hline & $(1.53 \mathrm{e}-09)$ & $(9.95 \mathrm{e}-10)$ & $(5.35 \mathrm{e}-09)$ & $(3.87 e-09)$ \\
\hline \multirow[t]{2}{*}{ Expectativa aposentadoria } & $0.0122 * * *$ & $0.00709 * * *$ & $-0.00886 * * *$ & $-0.00403 * * *$ \\
\hline & $(0.00204)$ & $(0.00126)$ & $(0.00246)$ & $(0.00151)$ \\
\hline \multirow[t]{2}{*}{ Idade } & $0.00288 * *$ & -0.000532 & $-0.00265^{*}$ & $0.00465^{* * *}$ \\
\hline & $(0.00122)$ & $(0.000703)$ & $(0.00151)$ & $(0.000889)$ \\
\hline \multirow[t]{2}{*}{ Idade $^{2}$} & $-3.18 \mathrm{e}-06$ & $1.04 \mathrm{e}-05^{*}$ & $6.21 \mathrm{e}-05^{* * *}$ & $-4.45 e-06$ \\
\hline & $(1.03 \mathrm{e}-05)$ & $(6.12 \mathrm{e}-06)$ & $(1.25 \mathrm{e}-05)$ & $(7.37 \mathrm{e}-06)$ \\
\hline \multirow[t]{2}{*}{ Gênero } & -0.0257 & -0.00702 & $0.252 * * *$ & $0.0951 * * *$ \\
\hline & $(0.0476)$ & $(0.0323)$ & $(0.0688)$ & $(0.0314)$ \\
\hline \multirow[t]{2}{*}{ Estado civil } & $0.0517 * * *$ & $0.0429 * * *$ & $0.0606^{* * *}$ & $0.0478^{* * *}$ \\
\hline & $(0.00848)$ & $(0.00500)$ & $(0.00955)$ & $(0.00592)$ \\
\hline \multirow[t]{2}{*}{ Instrução } & $0.0878 * * *$ & $0.0512 * * *$ & $0.222 * * *$ & $0.131 * * *$ \\
\hline & $(0.00609)$ & $(0.00365)$ & $(0.00690)$ & $(0.00427)$ \\
\hline \multirow[t]{2}{*}{ \# de dependentes } & $0.0292 * * *$ & $0.0108^{* * *}$ & -0.000495 & -0.00205 \\
\hline & $(0.00229)$ & $(0.00136)$ & $(0.00292)$ & $(0.00183)$ \\
\hline \multicolumn{5}{|l|}{ Ocupação } \\
\hline \multirow[t]{2}{*}{ Trabalhador } & 0.0351 & $0.0498^{* * *}$ & $-0.0725 * * *$ & $0.0500^{* * *}$ \\
\hline & $(0.0241)$ & $(0.0118)$ & $(0.0239)$ & $(0.0138)$ \\
\hline \multirow[t]{2}{*}{ Estudante } & $0.114 * * *$ & 0.00221 & $-0.129 * * *$ & 0.0340 \\
\hline & $(0.0386)$ & $(0.0225)$ & $(0.0476)$ & $(0.0254)$ \\
\hline \multirow[t]{2}{*}{ Dono de casa } & $0.113 * * *$ & 0.0300 & 0.0182 & $0.0917 * * *$ \\
\hline & $(0.0322)$ & $(0.0216)$ & $(0.0361)$ & $(0.0229)$ \\
\hline \multirow[t]{2}{*}{ Aposentado } & 0.0209 & $0.0778 * * *$ & $-0.0770 * * *$ & $0.0427 * * *$ \\
\hline & $(0.0255)$ & $(0.0127)$ & $(0.0256)$ & $(0.0148)$ \\
\hline
\end{tabular}




\section{Tabela 6 (continuação)}

\begin{tabular}{lllll}
\hline & \multicolumn{3}{l}{ Renda fixa } & \multicolumn{2}{l}{ Renda variável } \\
\cline { 2 - 5 } & Antes & Depois & Antes & Depois \\
\hline Raça & & & & \\
\hline Negro & $-0.0736^{*}$ & -0.00260 & 0.0201 & $-0.146^{* * *}$ \\
& $(0.0434)$ & $(0.0298)$ & $(0.0678)$ & $(0.0305)$ \\
\hline Branco & 0.00990 & $0.0792^{* * *}$ & $0.245^{* * *}$ & -0.00659 \\
& $(0.0392)$ & $(0.0281)$ & $(0.0608)$ & $(0.0260)$ \\
\hline Latino & $-0.309^{* * *}$ & $-0.143^{* * *}$ & -0.128 & $-0.237^{* * *}$ \\
& $(0.0794)$ & $(0.0486)$ & $(0.105)$ & $(0.0568)$ \\
\hline Idade*Gênero & $-0.000835^{*}$ & $-0.000427^{*}$ & $0.00184 * * *$ & $-0.000839^{* *}$ \\
& $(0.000454)$ & $(0.000246)$ & $(0.000560)$ & $(0.000339)$ \\
\hline Gênero*Negro & 0.0233 & 0.0281 & $-0.264 * * *$ & -0.00504 \\
& $(0.0487)$ & $(0.0325)$ & $(0.0723)$ & $(0.0342)$ \\
\hline Gênero*Branco & $0.0930^{* *}$ & 0.0202 & $-0.272^{* * *}$ & 0.00167 \\
& $(0.0421)$ & $(0.0300)$ & $(0.0627)$ & $(0.0274)$ \\
\hline Gênero*Latino & $0.208^{* *}$ & 0.0151 & -0.116 & $0.107 *$ \\
\hline N & $(0.0830)$ & $(0.0535)$ & $(0.109)$ & $(0.0594)$ \\
R-quadrado de McFadden & 22.085 & 30.075 & 22.085 & 30.075 \\
Log da verossimilhança & 0,094 & 0,110 & 0,229 & 0,257 \\
Critério de Akaike & $-10.633,25$ & $-10.798,72$ & $-10.599,31$ & $-11.771,81$ \\
\% Previstos corretamente & $21.312,500$ & $21.643,450$ & $21.244,610$ & $23.589,620$ \\
\hline & $78,0 \%$ & $86,0 \%$ & $75,6 \%$ & $81,4 \%$ \\
\hline
\end{tabular}

Nota. Erro-padrão da estimativa está entre parênteses. Antes = 2007; Depois = 2013.

Coeficientes estimados via comando 'margins, $\operatorname{dydx}(*)$, atmeans' do Stata. ***p-value $<0,01$; **p-value $<0,05$; *p-value $<$ 0,1 .

Estudantes e donos de casa aumentavam a probabilidade em 11\%; já, em 2013, essas variáveis não foram significantes. Aposentados e trabalhadores passaram a ter significância estatística e aumentar a probabilidade em 7\% e 4\%, respectivamente, nesse mesmo ano (2013). O mercado de renda variável, por sua vez, mostrou-se mais interessante para indivíduos do sexo masculino, apoiando os resultados obtidos por O'Neill e Xiao (2012). Em 2007, o coeficiente de idade era negativo, sugerindo que ações eram produtos mais voltados para jovens.

Além disso, outras características que implicavam em uma maior probabilidade de possuir ações era o fato do respondente ser branco, casado, com ensino superior, horizonte de planejamento mais extenso, maior inclinação a risco, expectativas mais pessimistas em relação à renda durante a aposentadoria, e uma expectativa positiva quanto ao desempenho futuro da economia. Em 2013, após a crise, o coeficiente da idade passou a ser significante e positivo. Assim, trabalhadores apresentaram-se mais propensos a investir em renda variável em 5\%, enquanto, em 2007, esse valor era de -7\%, o mesmo aconteceu para os aposentados, ao passo que etnias negras e latinas se tornaram significativamente avessas ao produto.

A Tabela 7 apresenta o modelo que relacionou os resultados obtidos para as Anuidades e o Trust. Para os ativos que pagam anuidades, os resultados sugerem que a idade é um fator relevante somente a partir de 2013. Ou seja, quanto mais idoso for o indivíduo, maior será sua propensão a investir nesse produto. Além disso, para esse tipo de produto, em 2007, o modelo não apontou variáveis significantes. 
Tabela 7

Modelo Preditivo para Anuidades e Trusts

\begin{tabular}{|c|c|c|c|c|}
\hline & \multicolumn{2}{|l|}{ Anuidade } & \multicolumn{2}{|l|}{ Trusts } \\
\hline & Antes & Depois & Antes & Depois \\
\hline \multirow[t]{2}{*}{ Horizonte de planejamento } & $0.00506 * * *$ & $0.00472 * * *$ & $0.00610 * * *$ & $0.0136^{* * *}$ \\
\hline & $(0.000755)$ & $(0.000645)$ & $(0.000567)$ & $(0.000863)$ \\
\hline \multirow[t]{2}{*}{ Inclinação a risco } & $0.00379 * * *$ & $0.00439 * * *$ & $0.00950 * * *$ & $0.0167 * * *$ \\
\hline & $(0.00111)$ & $(0.00103)$ & $(0.000777)$ & $(0.00123)$ \\
\hline \multirow[t]{2}{*}{ Expectativa } & $-0.00494 * * *$ & $0.00177 *$ & 0.000396 & $0.00262 * *$ \\
\hline & $(0.00120)$ & $(0.00101)$ & $(0.000808)$ & $(0.00123)$ \\
\hline \multirow[t]{2}{*}{ Necessidade de poupança } & 0 & $-1.98 \mathrm{e}-09 * * *$ & $2.31 \mathrm{e}-09 * * *$ & $8.99 \mathrm{e}-09 * * *$ \\
\hline & $(5.81 \mathrm{e}-10)$ & $(6.41 \mathrm{e}-10)$ & $(3.59 \mathrm{e}-10)$ & $(1.50 \mathrm{e}-09)$ \\
\hline \multirow[t]{2}{*}{ Expectativa aposentadoria } & $0.00181 * * *$ & $0.00384 * * *$ & $-0.00111 * *$ & $-0.00228 * * *$ \\
\hline & $(0.000644)$ & $(0.000580)$ & $(0.000464)$ & $(0.000739)$ \\
\hline \multirow[t]{2}{*}{ Idade } & $0.00703 * * *$ & $0.00683 * * *$ & 0.000505 & $0.00104 * *$ \\
\hline & $(0.000435)$ & $(0.000419)$ & $(0.000346)$ & $(0.000506)$ \\
\hline \multirow[t]{2}{*}{ Idade $^{2}$} & $-4.32 \mathrm{e}-05 * * *$ & $-4.28 \mathrm{e}-05^{* * *} *$ & $3.15 \mathrm{e}-06$ & $5.69 \mathrm{e}-06$ \\
\hline & $(3.35 \mathrm{e}-06)$ & $(3.44 \mathrm{e}-06)$ & $(2.63 \mathrm{e}-06)$ & $(4.01 \mathrm{e}-06)$ \\
\hline \multirow[t]{2}{*}{ Gênero } & $0.0310 * *$ & -0.0115 & -0.0164 & $-0.0402 *$ \\
\hline & $(0.0155)$ & $(0.0107)$ & $(0.0125)$ & $(0.0220)$ \\
\hline \multirow[t]{2}{*}{ Estado civil } & 0.000605 & 0.000812 & $0.00914 * * *$ & $0.0278 * * *$ \\
\hline & $(0.00285)$ & $(0.00256)$ & $(0.00213)$ & $(0.00315)$ \\
\hline \multirow[t]{2}{*}{ Instrução } & $0.0126^{* * *}$ & $0.0202 * * *$ & $0.0210 * * *$ & $0.0418 * * *$ \\
\hline & $(0.00212)$ & $(0.00201)$ & $(0.00150)$ & $(0.00238)$ \\
\hline \multirow[t]{2}{*}{ \# de dependentes } & $3.58 \mathrm{e}-05$ & $0.00253 * * *$ & 0.00102 & $0.00384 * * *$ \\
\hline & $(0.000912)$ & $(0.000799)$ & $(0.000624)$ & $(0.000869)$ \\
\hline \multicolumn{5}{|l|}{ Ocupação } \\
\hline \multirow[t]{2}{*}{ Trabalhador } & 0.00579 & -0.00788 & $-0.0130 * *$ & $0.0193 * *$ \\
\hline & $(0.00986)$ & $(0.00510)$ & $(0.00535)$ & $(0.00826)$ \\
\hline \multirow[t]{2}{*}{ Estudante } & & & 0.0130 & $0.0398 * * *$ \\
\hline & & & $(0.0100)$ & $(0.0145)$ \\
\hline \multirow[t]{2}{*}{ Dono de casa } & -0.000331 & 0.00951 & $0.0224 * * *$ & 0.0123 \\
\hline & $(0.0130)$ & $(0.00783)$ & $(0.00674)$ & $(0.0125)$ \\
\hline \multirow[t]{2}{*}{ Aposentado } & $0.0252 * *$ & 0.00141 & $-0.0147 * * *$ & $0.0218 * *$ \\
\hline & $(0.0102)$ & $(0.00531)$ & $(0.00556)$ & $(0.00855)$ \\
\hline
\end{tabular}




\section{Tabela 7 (continuação)}

\begin{tabular}{|c|c|c|c|c|}
\hline & \multicolumn{2}{|l|}{ Anuidade } & \multicolumn{2}{|l|}{ Trusts } \\
\hline & Antes & Depois & Antes & Depois \\
\hline \multicolumn{5}{|l|}{ Raça } \\
\hline \multirow[t]{2}{*}{ Negro } & $-0.0306^{* *}$ & $-0.0524 * * *$ & $-0.364 * * *$ & -0.0175 \\
\hline & $(0.0132)$ & $(0.00870)$ & $(0.0184)$ & $(0.0219)$ \\
\hline \multirow[t]{2}{*}{ Branco } & -0.00229 & $-0.0232 * * *$ & $0.0231 * *$ & $0.0406^{* *}$ \\
\hline & $(0.0106)$ & $(0.00715)$ & $(0.0109)$ & $(0.0200)$ \\
\hline \multirow[t]{2}{*}{ Latino } & $-0.462 * * *$ & $-0.0415 * * *$ & $-0.364 * * *$ & -0.0156 \\
\hline & $(0.0226)$ & $(0.0114)$ & $(0.0188)$ & $(0.0269)$ \\
\hline \multirow[t]{2}{*}{ Idade*Gênero } & $-0.000665 * * *$ & $-0.000303^{* *}$ & $0.000242 * *$ & 0.000104 \\
\hline & $(0.000167)$ & $(0.000141)$ & $(0.000121)$ & $(0.000176)$ \\
\hline \multirow[t]{2}{*}{ Gênero*Negro } & 0.0180 & $0.0312 * * *$ & $0.319 * * *$ & -0.00467 \\
\hline & $(0.0159)$ & $(0.0109)$ & $(0.0238)$ & $(0.0254)$ \\
\hline \multirow[t]{2}{*}{ Gênero*Branco } & 0.0111 & $0.0266^{* * *}$ & -0.00373 & 0.0227 \\
\hline & $(0.0122)$ & $(0.00830)$ & $(0.0117)$ & $(0.0212)$ \\
\hline \multirow[t]{2}{*}{ Gênero*Latino } & $0.456 * * *$ & $0.0286 * *$ & $0.337 * * *$ & 0.0208 \\
\hline & $(0.0248)$ & $(0.0131)$ & $(0.0222)$ & $(0.0289)$ \\
\hline $\mathrm{N}$ & 21.875 & 29.585 & 22.085 & 30.075 \\
\hline R-quadrado de McFadden & 0,126 & 0,136 & 0,182 & 0,235 \\
\hline Log da verossimilhança & $-4884,61$ & $-5885,57$ & $-5974,87$ & $-7507,11$ \\
\hline Critério de Akaike & 9815,209 & 11817,140 & 11995,730 & 15060,210 \\
\hline$\%$ Previstos corretamente & $93,0 \%$ & $94,0 \%$ & $89,8 \%$ & $90,2 \%$ \\
\hline
\end{tabular}

Nota. Erro-padrão da estimativa está entre parênteses. Antes = 2007; Depois $=2013$.

Coeficientes estimados via comando 'margins, $\operatorname{dydx}(*)$, atmeans' do Stata. ***p-value <0,01; **p-value < 0,05; *p-value <0,1.

Em 2013, a variável instrução passou a ser relevante junto com tamanho da unidade familiar, expectativa acerca da economia, inclinação ao risco, necessidade de poupança, negro, branco e latino, como todos os termos de interação. O indivíduo ser negro, branco ou latino diminuía a probabilidade de consumo de Anuidades em 2\%, 5\% e 4\%, respectivamente.

Destaca-se ainda que os termos de interação foram significantes e apontaram que os indivíduos do sexo masculino das mais diversas etnias apresentaram uma maior probabilidade em consumir o produto. Com relação aos Trusts e contas geridas por terceiros, em 2007 também não foi possível inferir acerca dos indivíduos. Em 2013, idade, gênero, casado, maior instrução, maior número de dependentes, expectativa para a economia, horizonte de planejamento, inclinação ao risco, expectativa pessimista para a aposentadoria, trabalhador, aposentado, branco e estudante passaram a ser relevantes estatisticamente.

\section{Considerações Finais}

Esta pesquisa explorou uma temática de interesse comum e atual, que reflete a influência do contexto de crise econômica sobre as decisões de investimento dos indivíduos, tal como fizeram MacGregor et al. (1999), Hoffmann et al. (2013), Necker e Ziegelmeyer (2016), Chu, Wang, Xiao e 
Zhang (no prelo). Entre os resultados obtidos, um dos mais importantes foi a constatação de indícios de uma mudança do comportamento de escolha dos indivíduos em relação ao consumo de determinados produtos financeiros entre os períodos pré e pós-crise do Subprime nos Estados Unidos, corroborando os achados de O'Neill e Xiao (2012) e Devlin-Foltz e Sabelhaus (2016), destacando-se porém que, nesta pesquisa, são oferecidas evidências ao redor de um amplo conjunto de ativos-alvo de investimento, com base nos dados de dezenas de milhares de respondentes do Survey of Consumer Finances.

A esse respeito, Zick et al. (2012) notaram que as gerações mais velhas se tornaram menos propensas a poupar, e mais inclinadas a retardar a aposentadoria, enquanto as gerações mais novas demonstraram uma maior tolerância a risco. Segundo os resultados reportados na presente pesquisa, foi possível observar que a idade foi, de fato, uma variável significante em todos os modelos, sendo seus respectivos coeficientes predominantemente positivos. Outro resultado que segue em linha com os achados desses autores é a significância do horizonte de planejamento financeiro.

Argumentos encontrados na literatura sugerem que existem limitações para a escolha de novos produtos de investimento devido à falta de conhecimento em finanças ou à ingenuidade de algumas famílias de classes sociais mais baixas (Campbell, 2006). Nos estudos sobre ativos financeiros e reais, pode-se perceber que os resultados obtidos acerca das características pessoais determinantes para a seleção de cada um dos ativos mostram-se inconclusivos, conforme defende Campbell (2006), o que aponta para a existência de uma agenda de pesquisa.

Convém destacar os coeficientes negativos dos termos quadráticos da idade para alguns produtos. Esses coeficientes indicam que suas respectivas variáveis dependentes são determinadas por funções côncavas com pontos de máximo (Bruin, 2011). Esses resultados podem ser comparados aos obtidos por Hilgert et al. (2003), Yoong (2011) e Lusardi (2012), os quais sugerem que o nível de educação financeira é menor entre os mais jovens e os mais velhos. Para Finke, Howe e Huston (2017), a educação financeira tem impacto direto sobre alguns comportamentos, como investir em ações, por exemplo. Essa afirmação vale para o que foi observado a respeito das Anuidades (Tabela 7), mas não corresponde ao observado para Ações (Tabela 6).

Por fim, a importância em se investigar o comportamento de investimento de famílias concentrase na possibilidade de construção de conhecimento acerca dos determinantes de escolha, sensibilidade a fatores macroeconômicos e aspectos inerentes às atitudes dos indivíduos. Esse campo de conhecimento, de acordo com Lusardi (2012) e O’Neill e Xiao (2012), colabora para o gerenciamento de recursos orientado à eficiência financeira dos investimentos. Deste modo, tarefas como orçar, poupar e gastar podem ser realizadas pelas famílias de modo sustentável ao longo do tempo (Magendans, Gutteling, \& Zebel, no prelo).

A título de sugestões para estudos futuros, recomenda-se a realização de pesquisas a partir de abordagens comparadas, ao redor da temática de investimentos pessoais, em diferentes culturas e economias. É importante ressaltar a necessidade da criação de uma base de dados semelhante ao Survey of Consumer Finances para o contexto brasileiro, pois a variedade de informações disponíveis permite a elaboração de estudos que podem permitir implicações para políticas públicas em educação financeira de indivíduos, bem como estratégias públicas e privadas para oferta de produtos financeiros, como alternativas de investimento e poupança para as famílias (Grinstein-Weiss, Guo, Reinertson, \& Russell, 2015).

\section{Agradecimentos}

Os autores gostariam de registrar o reconhecimento do apoio recebido do Instituto Brasileiro de Inovação Financeira-IBRIF®, por meio de apoio financeiro que permitiu os esforços iniciais de composição da base de dados sobre a qual se apoia o presente estudo. Também desejam agradecer aos participantes do EnAnpad 2016 pelos comentários e pelas sugestões, e aos revisores anônimos da RAC pela sugestões e críticas a este trabalho, cujo conteúdo não reflete necessariamente a opinião e o posicionamento das instituições às quais estão vinculados seus autores. 


\section{Referências}

Aldrich, J. H., \& Nelson, F. D. (1984). Linear probability, logit, and probit models. Beverly Hills, CA: Sage. http://dx.doi.org/10.4135/9781412984744

Barnett, W. (1981). Consumer demand and labor supply: goods, monetary assets, and time. Amsterdam: North Holland Publishing Co., Amsterdam.

Basinger, S. J., \& Ensley, M. J. (2010). Endogeneity problems with binary treatments: a comparision of models [Working Paper]. University of Houston. Retrieved from http://www.personal.kent.edu/ mensley/Research_files/Endogeneity\%20Problems\%20with\%20 Binary\%20Treatments, \%200ctober\%202010.pdf

Bettis, R. A., Ethiraj, S., Gambardella, A., Helfat, C., \& Mitchell, W. (2016). Creating repeatable cumulative knowledge in strategic management. Strategic Management Journal, 37(2), 257-261. http://dx.doi.org/10.1002/smj.2477

Brodeur, A., Lé, M., Sangnier, M., \& Zylberberg, Y. (2016). Star wars: the empirics strike back. American Economic Journal: Applied Economics, 8(1), 1-32. http://dx.doi.org/10.1257/app.20150044

Bruin, J. (2011). FAQ How do I interpret the sign of the quadratic term in a polynomial regression? São Paulo. Retrieved 24 February, 2015, from http://stats.idre.ucla.edu/other/mult$\mathrm{pkg} / \mathrm{faq} / \mathrm{general} / \mathrm{faqhow}$-do-i-interpret-the-sign-of-the-quadratic-term-in-a-polynomialregression/

Bunting, D. (2001). Keynes' law and its critics. Journal of Post Keynesian Economics, 24(1), 149-163. http://dx.doi.org/10.1080/01603477.2001.11490319

Campbell, J. Y. (2006). Household finance. Journal of Finance, 61(4), 1553-1604. http://dx.doi.org/10.1111/j.1540-6261.2006.00883.x

Chu, Z., Wang, Z., Xiao, J., \& Zhang, W. (no prelo). Financial literacy, portfolio choice and financial well-being. Social Indicators Research. http://dx.doi.org/10.1007/s11205-016-1309-2

Cooper, R., \& Zhu, G. (2016). Household finance over the life-cycle: what does education contribute? Review of Economic Dynamics, 20, 63-89. http://dx.doi.org/10.1016/j.red.2015.12.001

Devlin-Foltz, S., \& Sabelhaus, J. (2016). Heterogeneity in economic shocks and household spending. Fiscal Studies, 37(1), 153-192. http://dx.doi.org/10.1111/j.1475-5890.2016.12082 10.17016/FEDS.2015.049

Dimmock, S. G., Kouwenberg, R., Mitchell, O. S., \& Peijnenburg, K. (2016). Ambiguity aversion and household portfolio choice puzzles: empirical evidence. Journal of Financial Economics, 119 (3), 559-577. http://dx.doi.org/10.1016/j.jfineco.2016.01.003

Egol, M., Clyde, A., Rangan, K., \& Sanderson, R. (2010). The new consumer frugality adapting to the enduring shift in U.S. consumer spending and behavior. Retrieved 24 February, 2015, from http://www.strategyand.pwc.com/media/file/The_New_Consumer_Frugality.pdf

Fama, E., \& French, K. R. (1992). The cross section of expected stock returns. Journal of Finance, 47(2), 427-465. http://dx.doi.org/10.1111/j.1540-6261.1992.tb04398.x

Finke, M. S., Howe, J. S., \& Huston, S. J. (2017). Old age and the decline in financial literacy. Management Science, 63(1), 213-230. http://dx.doi.org/10.1287/mnsc.2015.2293 
Fisher, P. J. (2010). Gender differences in personal saving behaviors. Journal of Financial Counseling and Planning, 21(1), 9-19.

Fontes, A., \& Kelly, N. (2013). Factors affecting wealth accumulation in hispanic households: a comparative analysis of stock and home asset utilization. Hispanic Journal of Behavioral Sciences, 35(4), 565-587. http://dx.doi.org/10.1177/0739986313500467

Friedman, M. (1957). A theory of the consumption function. New York: Princeton University Press.

Gollier, C. (2004). Economics of risk and time. Cambridge, MA: MIT Press.

Grinstein-Weiss, M., Guo, S., Reinertson, V., \& Russell, B. (2015). Financial education and savings outcomes for low-income ida participants: does age make a difference? Journal of Consumer Affairs, 49(1), 156-185. http://dx.doi.org/10.1111/joca.12061

Guiso, L., Sapienza, P., \& Zingales, L. (2015). Time varying risk aversion [Working Paper $\mathrm{n}^{\circ}$ 19284]. National Bureau of Economic Research. Retrieved from http://www.kellogg.northwestern.edu/faculty/sapienza/htm/risk_aversion.pdf

Hastings, J. S., \& Tejeda-Ashton, L. (2008). Financial literacy, information, and demand elasticity: survey and experimental evidence from Mexico [Working Paper $\mathrm{n}^{\circ}$ 14538]. National Bureau of Economic Research. http://dx.doi.org/10.3386/w14538

Hilgert, M. A., Hogarth, J. M., \& Beverly, S. G. (2003). Household financial management: the connection between knowledge and behavior. Federal Reserve Bulletin, 89(7), 309-322.

Hoffmann, A., Post, T., \& Pennings, J. (2013). Individual investor perceptions and behavior during the financial crisis. Journal of Banking \& Finance, 37(1), 60-74. http://dx.doi.org/10.1016/j.jbankfin.2012.08.007

Kahneman, D., \& Tversky, A. (1979). Prospect theory: an analysis of decision under risk. Econometrica, 47(2), 263-291. http://dx.doi.org/10.2307/1914185

Kalayc1, K., \& Serra-Garcia, M. (2016). Complexity and biases. Experimental Economics, 19(1), 3150. http://dx.doi.org/10.1007/s10683-015-9434-3

Keynes, J. M. (1936). The general theory of employment, interest and money. New York: Harcourt Brace Jovanovich.

Kimball, M. S., \& Shumway, T. (2006). Investor sophistication and the participation, home bias, diversification, and employer stock puzzle [Working Paper]. University of Michigan. http://dx.doi.org/10.2139/ssrn.1572866

Korniotis, G., \& Kumar, A. (2011). Do older investors make better investment decisions? The Review of Economics and Statistics, 93(1), 244-265. http://dx.doi.org/10.1162/REST_a_00053

Lewbel, A., Dong, Y., \& Yang, T. T. (2012). Comparing features of convenient estimators for binary choice models with endogenous regressors. Canadian Journal of Economics, 45(3), 809-829. http://dx.doi.org/10.1111/j.1540-5982.2012.01733.x

Lusardi, A. (2009). U.S. household savings behavior: the role of financial literacy, information and financial education programs. In C. Foote, L Goette, \& S. Meier (Eds.), Policy making insights from behavioral economics (pp. 109-149). Boston: Federal Reserve Bank of Boston. http://dx.doi.org/10.3386/w13824

Lusardi, A. (2012). Numeracy, financial literacy, and financial decision-making [Working Paper $\mathrm{n}^{\circ}$ 17821]. National Bureau of Economic Research, Cambridge, MA. 
Lusardi, A., \& Mitchell, O. S. (2007). Baby boomer retirement security: the role of planning, financial literacy, and housing wealth. Journal of Monetary Economics, 54(1), 205-224. http://dx.doi.org/10.3386/w12585

MacGregor, D. G., Slovic, P., Berry, M., \& Evensky, H. R. (1999, September). Perception of financial risk: a survey study of advisors and planners. Journal of Financial Planning, 68-86.

Magendans, J., Gutteling, J. M., \& Zebel, S. (no prelo). Psychological determinants of financial buffer saving: the influence of financial risk tolerance and regulatory focus. Journal of Risk Research. http://dx.doi.org/10.1080/13669877.2016.1147491

Modigliani, F., \& Brumberg, R. (1954). Utility analysis and the consumption function: an interpretation of cross-section data. K. Kurihara (Ed.), Post Keynesian economics (pp. 388-436). New Brunswick: Rutgers University Press.

Moore, J. F., \& Mitchell, O. S. (1997). Projected retirement wealth and savings adequacy in the health and retirement study. Cambridge MA: National Bureau of Economic Research. http://dx.doi.org/10.3386/w6240

Mugerman, Y., Ofir, M., \& Wiener, Z. (2016). How homeowners choose between fixed and adjustable rate mortgages? Quarterly Journal of Finance, 6(4), 1-21. http://dx.doi.org/10.1142/s2010139216500130

Necker, S., \& Ziegelmeyer, M. (2016). Household risk taking after the financial crisis. The Quarterly Review of Economics and Finance, 59, 141-160. http://dx.doi.org/10.1016/j.qref.2015.03.006

O’Neill, B., \& Xiao, J. J. (2012). Financial behaviors before and after the financial crisis: evidence from an online survey. Journal of Financial Counseling and Planning, 23(1), 33-46.

Roberts, M. R., \& Whited, T. M. (2013). Endogeneity in empirical corporate finance. Handbook of the Economics of Finance, 2(Part A), 493-572. http://dx.doi.org/10.1016/b978-0-44-4535948.00007-0

Said, F., Afzal, U., \& Turner, G. (2015). Risk taking and risk learning after a rare event: evidence from a field experiment in Pakistan. Journal of Economic Behavior and Organization, 118, 167-183. http://dx.doi.org/10.1016/j.jebo.2015.03.001

Schuchardt, J., Hanna, S. D., Hira, T. K., Lyons, A. C., Palmer, L., \& Xiao, J. J. (2009). Financial literacy and education research priorities. Journal of Financial Counseling and Planning, 20(1), 84-95.

Social Security Administration. (2013). Social security changes. Retrieved from https://www.ssa.gov/news/press/factsheets/colafacts2013.pdf

Survey of Consumer Finances (n.d.). Database. Retrieved 24 February, 2017 from https://www.federalreserve.gov/econresdata/scf/scfindex.htm

Taylor, P., Morin, R., Kochhar, R., Parker, K., Cohn, D., Lopez, M. H., Fry, R., Wang, W., Velasco, G., Dockterman, D., Hinze-Pifer, R., \& Espinoza, S. (2010). A balance sheet at 30 months: how the great recession has changed life in America. Washington, DC: Pew Research Center, Social and Demographic Trends Project. Retrieved from http://pewsocialtrends.org/assets/pdf/759recession.pdf

The Hartford. (2009). The Hartford investment and retirement survey. Retrieved 23 October, 2015, from http://www. hartfordinvestor.com/general_pdf/Hartford_Retire- ment_Survey_09.pdf

Wasserstein, R. L., \& Lazar, N. A. (2016). The ASA's statement on p-values: context, process, and $\begin{array}{llll}\text { purpose. The American } & \text { Statistician, } & \text { 129-133. }\end{array}$ http://dx.doi.org/10.1080/00031305.2016.1154108 
Weber, M., Weber, E. U., \& Nosic, A. (2013). Who takes risks when and why: determinants of changes in investor risk taking. Review of Finance, 17(3), 847-883. http://dx.doi.org/10.1093/rof/rfs024

Williams, R. (2012). Using the margins command to estimate and interpret adjusted predictions and marginal e effects. The Stata Journal, 12(2), 308-331.

Wisman, J. D. (2014). The financial crisis of 1929 reexamined: the role of soaring inequality. Review of Political Economy, 26(3), 372-391. http://dx.doi.org/10.1080/09538259.2014.915153

Yoong, J. (2011). Financial illiteracy and stock market participation: evidence from the RAND American life panel. Oxford, UK: Oxford University Press. http://dx.doi.org/10.1093/acprof:oso/9780199696819.003.0005

Zick, C. D., Mayer, R. N., \& Glaubitz, K. (2012). The kids are all right: generational differences in responses to the great recession. Journal of Financial Counseling and Planning, 23(1), 3-16.

\section{Dados dos Autores}

Israel José dos Santos Felipe

Av. 9 de Julho, 2029, Bela Vista, 01313-902, São Paulo, SP, Brasil. E-mail: israeljfelipe@ hotmail.com, israeljfelipe@gmail.com

Marcelo Daniel Araújo Ermel

Av. 9 de Julho, 2029, Bela Vista, 01313-902, São Paulo, SP, Brasil. E-mail: Ermel.marcelo@ gmail.com

Luis Felipe Pilati Cassius

Av. 9 de Julho, 2029, Bela Vista, 01313-902, São Paulo, SP, Brasil. E-mail: Ifcassius@ gmail.com

Wesley Mendes-da-Silva

Av. 9 de Julho, 2029, Bela Vista, 01313-902, São Paulo, SP, Brasil. E-mail: mr.mendesdasilva@ gmail.com 